\title{
Karsten Brüggemann
}

\section{"Wir brauchen viele Geschichten“ Estland und seine Geschichte auf dem Weg nach Europa?}

\begin{abstract}
Als am 23. August 1989 die Bevölkerung der baltischen Sowjetrepubliken mit einer spektakulären Menschenkette von Tallinn nach Vilnius singend gegen die Folgen des 50 Jahre zuvor geschlossenen Hitler-Stalin-Pakts demonstrierte ${ }^{1}$, schien es bis zur „Rückkehr nach Europa“ noch weit. Doch dann schien sie bereits vor der Aufnahme Estlands, Lettlands und Litauens in NATO und EU vollzogen worden zu sein: Am 25. Mai 2002 wurde Tallinn, das alte dänische, deutsche, schwedische oder russische Reval, zur „europäischen Schlagerhauptstadt" und gab diesen Titel aufgrund des lettischen Sieges beim „European Song contest" an die baltische Schwesterstadt Riga weiter. Die erfolgreiche Ausrichtung dieser international beachteten Schlagerveranstaltung hat Estland zweifellos einen Imagegewinn verschafft, der - glaubt man der estnischen Presse - höchstens vom Gewinn der Fußballweltmeisterschaft zu übertreffen gewesen wäre. Bis dahin ist es freilich noch weit ${ }^{2}$, doch hat der Siegeszug der baltischen leichten Muse dieser Region Europas wieder einmal Aufmerksamkeit zuteil werden lassen.

Schnell waren in diesem Zusammenhang die Leitmotive „Singen“ und „Politik“ zur Hand, denn die „singende Revolution“ der zweiten Hälfte der 1980er Jahre war Tenor dieser Berichterstattung: „Es kam“, so schrieb beispielsweise „Die Zeit“, „das Jahr 1991, die Revolution, Hunderttausende sangen Volkslieder, laut und immer wieder, bis die Kommunisten Reißaus nahmen. Seitdem liegt Tallinn in Estland" 3 - und, so möchte man ergänzen, Singen ist nicht mehr Protest gegen Fremdherrschaft, sondern Werbung für das eigene Land. Sei dem, wie es sei, Legenden über putzige Randgebiete der Zivilisation, so haltlos sie auch sein mögen, produzieren Bilder, die in Erinnerung bleiben. Natürlich ist Singen ein fester Bestandteil estnischer und lettischer Kultur mit einer selbstbewußten, in den Sänger-
\end{abstract}

1 MPR-suvi. Balti kett, in: Teine Eesti. Eesti iseseisvuse taassünd 1986-1991, hrsg. v. Mart Laar, Urmas Ott, Sirje Endre (Tallinn 1996) 549-583.

2 Auch wenn in einem ,historischen“ Spiel im März 2002 die estnische Fußballnationalelf immerhin die Auswahl Rußlands mit 2:1 bezwingen konnte.

3 Frank Lenze, Hier spielt die Musik. Zwei Gesichter der europäischen Schlagerstadt Tallinn, in: Die Zeit 2002, Nr. 22, 65 f. 
festen verkörperten Tradition, die nicht erst während der Perestroika der friedlichen Manifestation nationalen Selbstbewußtseins und nationaler Ansprüche diente ${ }^{4}$. Aber wegen der Lieder nahmen die Kommunisten kaum Reißaus. Demgegenüber ist die schlichte Evidenz der Aussage, Tallinn liege seit 1991 wieder in Estland, erhellend. Sie verweist - wie unbewußt auch immer - darauf, daß für viele Esten die Hauptstadt der Estnischen SSR eben nicht estnische Hauptstadt war. Mit der Unterzeichnung des Hitler-Stalin-Paktes 1939 hatte für viele Esten eine Zeit der Entfremdung eingesetzt: Ihre nationale Kultur und Symbolik verwandelten sich nicht nur dem Inhalt nach in fremde Propaganda. Entfremdet wurde auch und gerade ihre Geschichte, denn die Geschichte der Estnischen SSR war eben nicht ihre Geschichte Estlands. Hinter den Liedern der „singenden Revolution“ stand schließlich ein nationales Selbstbewußtsein, das von der Hoffnung auf den Sieg der historischen Gerechtigkeit gespeist war. Reißaus nahmen die Kommunisten, wenn wir im Bild bleiben wollen, wohl eher vor dieser nationalen estnischen Geschichte.

Seit Mitte der 1980er Jahre forderte die nationale estnische Geschichtsinterpretation die sowjetische Legende der „Volksrevolution“, die 1940 die „Wiedervereinigung" Estlands mit der UdSSR herbeigeführt habe, auch öffentlich heraus. Dieses nationale Geschichtsparadigma mußte nicht neu erfunden werden, im Gegenteil: Nach Ansicht des heute in Toronto lehrenden estnischen Mediävisten Jüri Kivimäe hat es in dieser Phase keine eigentliche historiographische Wende gegeben $^{5}$. Er folgt damit der großen alten Dame der estnischen Geschichtsschreibung, Ea Jansen, der zufolge die von sowjetestnischen Historikern betriebene und international anerkannte Erforschung des estnischen Bauerntums sowie der Zeit des "nationalen Erwachens" die Topoi der nationalen Geschichtsschreibung der 1930 er Jahre ohnehin fortgesetzt hätte, freilich mit einer anderen Rhetorik ${ }^{6}$. Neu war demzufolge 1989 nur, daß dieser rhetorische Ballast abgeworfen werden konnte.

Sicher ist diese Konstruktion einer idealtypischen historiographischen Linie von den 1930ern über die 1960er bis heute einer näheren Untersuchung wert (aber im gegebenen Rahmen dieses Aufsatzes nicht leistbar). Zweifelsfrei steht hingegen fest, daß das dominante nationale Geschichtsbild dank einer weiteren, aus der Zeit der Aufklärung herrührenden Tradition über die Sowjetzeit hinweg relativ konstant blieb: der Heimunterricht bzw. die in der Familie überlieferte estnische Geschichte. Spätestens am Ende des 19. Jahrhunderts hatten estnische Intellektuelle

${ }^{4}$ Daß viele der „estnischen" Lieder auf deutschen Vorbildern beruhen, störte während der Perestroika niemanden. Vgl. Immo Mibkelson, Die estnische Popmusik als kleiner Traum, in: estonia 17 (2002) 27-31.

5 Mail von Jüri Kivimäe an den Verf., 12. Oktober 2000.

6 Ea Jansen, Hajamötteid Eesti ajaloo uurimisest, in: Kleio. Ajaloo ajakiri 19 (1997) Nr. 1, 35-41. Kivimäe wiederum erinnerte sich an die Beobachtung seines Lehrers Julius Madisson, daß die meisten sowjetestnischen Historiker Marx nicht gelesen, und die, die es taten, ihn nicht verstanden hätten. Intervjuu: Vestlus Jüri Kivimäega, in: Vikerkaar (2000) H. 8-9, 124136, hier 128. 
den vorherrschenden Narrationen der deutschbaltischen und russischen Eliten eine „estnische " historische Konzeption gegenübergestellt ${ }^{7}$, die als Grundlage für die nach der Erlangung der Unabhängigkeit seit 1918 auch institutionell begründete estnische Historiographie diente. Diese wiederum versuchte, dem „langen Schatten" der deutschbaltischen Geschichtsschreibung zu entkommen und erreichte ihre nationale Blüte während der zweiten Hälfte der 1930er Jahre unter dem Schirm der autoritären Diktatur von Konstantin Päts ${ }^{8}$. Ohne je in die Form einer kompletten kanonischen Meistererzählung gegossen zu sein - zwei groß angelegte Versuche blieben unvollendet ${ }^{9}-$, kursierte schließlich ein nationalzentriertes Kondensat in der Sowjetzeit als nonkonformes Geschichtsbild, als eigentliche "Wahrheit" nicht nur im dissidentischen Untergrund. Die Vernichtung bzw. Verbannung der gedruckten nationalen Geschichten in die spec-chrany der Archive und Bibliotheken konnte die für Regionen vorsowjetischer Staatlichkeit typische Virulenz der in oraler Tradition überlieferten „wahren" Geschichte des kollektiven Gedächtnisses nicht eindämmen ${ }^{10}$. Schließlich hafteten der offiziellen sowje-

7 Vgl. zu den Wurzeln estnischer Geschichtsauffassung bei Garlieb Merkel Jaan Undusk, Kolm vöimalust kirjutada eestlaste ajalugu. Merkel - Jakobson - Hurt, in: Keel ja kirjandus 40 (1997) 721-734, 797-811; ders., "Wechsel und Wiederkehr" als Prinzipien des Weltgeschehens: Zu Merkels Geschichtsideologie, in: „Ich werde gewiß große Energie zeigen." Garlieb Merkel (1769-1850) als Kämpfer, Kritiker und Projektmacher in Berlin und Riga, hrsg. v. J. Drews (Bielefelder Schriften zu Linguistik und Literaturwissenschaft 13, Bielefeld 2000) 133-147.

8 Vorüberlegungen zu einer estnischen Historiographiegeschichte der Zwischenkriegszeit bei Sirje und Jüri Kivimäe, Estnische Geschichtsforschung an der Universität Tartu 19201940. Ziele und Ergebnisse, in: Die Universitäten Dorpat/Tartu, Riga und Wilna/Vilnius 1579-1979. Beiträge zu ihrer Geschichte und ihrer Wirkung im Grenzbereich zwischen Ost und West, hrsg. v. Gert von Pistoblkors, Toivo U. Raun, Paul Kaegbein (Köln, Wien 1987) 277-292; dies., Hans Kruus und die deutsch-estnische Kontroverse, in: Zwischen Konfrontation und Kompromiß. Oldenburger Symposium: „Interethnische Beziehungen in Ostmitteleuropa als historiographisches Problem der 1930er/1940er Jahre“, hrsg. v. Michael Garleff (Schriften des Bundesinstituts für ostdeutsche Geschichte und Kultur 8, München 1995) 155-170; Rein Helme, Die estnische Historiographie, in: ebd. 139-154; Tiit Rosenberg, Eesti ajaloo historiograafiast, in: Ajalooline ajakiri (1999) H. 1, 5-8; ders., Professor A.R. Cederberg. Eesti ajaloo uurimise koolkonna rajaja Tartu ülikoolis, in: Ajalooline ajakiri (1999) H. 2, 79-90; Jörg Hackmann, Ethnos oder Region? Probleme der baltischen Historiographie im 20. Jahrhundert, in: ZfO 50 (2001) 531-556.

9 Bis in das 17. Jahrhundert führte das auf fünf Bände angelegte Werk Eesti ajalugu, hrsg. v. Harri Moora, Eerik Laid, Julius Mägiste, Hans Kruus, 3 Bde. (Tartu 1935-1940); die im Auftrag von Präsident Päts verfaßte Eesti rahva ajalugu, hrsg. v. Juban Libe, Aleksander Oinas, Hendrik Sepp, Juhan Vasar, 3 Bde. (Tartu 1932-1937) gelangte nur bis ins 16. Jahrhundert, umfaßte aber als Sonderband die wohl tatsächlich, spätestens durch ihre repräsentative Zweitauflage im schwedischen Exil, als kanonisch zu bezeichnende umfangreiche Darstellung der Staatsgründung und des Unabhängigkeitskriegs: Eduard Laaman, Eesti iseseisvuse sünd (Tartu 1936/37; Stockholm 21964). Zu Laaman vgl. Olavi Arens, Eduar Laaman as a Historian, in: Baltic History, hrsg. v. Arvids Ziedonis, jr., William L. Winter, Mardi Valgemäe (Publications of the Association for the Advancement of Baltic Studies 5, Colombus, Ohio 1974) 217-226. Zur Einschätzung dieser Arbeiten verweise ich auf die in Anm. 8 genannte Literatur.

10 Sulev Vabtre, Die Geschichtskunde und die Historiker in Estland in den kritischen Jahren 
tischen Wahrheit allseits bekannte Widersprüche an, die jedes Schulkind anhand der eigenen Familiengeschichte erkennen konnte. Und die der sowjetischen Ideologie immanente Rollenverteilung, die den Esten den Part des jüngeren Bruders zuwies, ließ sich nur schwer mit dem verbreiteten Stereotyp der russischen Rückständigkeit in Einklang bringen. Schließlich erregte die öffentliche Lüge Peeter Tulviste zufolge schlicht Neugier, ist doch die verbotene Frucht immer die süßeste ${ }^{11}$.

Auf diese, trotz des Verbots präsente Geschichte rekurrierte die nationale Emanzipationsbewegung während der Perestroika und gewann nicht zuletzt durch sie ihre Fähigkeit zur Mobilisierung breiter Bevölkerungskreise. Sie nutzte effektiv die integrative Kraft des historischen Gedächtnisses: Die Renationalisierung der eigenen Geschichte legitimierte die Wiedererlangung des unabhängigen Staates. Zunächst wurde dabei die teleologische Komponente dieses Konzepts, demzufolge die lichte Zukunft in der Rückbesinnung auf die nationale Vergangenheit lag, gern in Kauf genommen. Geschichte diente somit wiederum der Legitimation von Politik und mehr noch: Historiographie wurde Politik - hier reicht das Stichwort „Hitler-Stalin-Pakt“. Dieser neuralgische Punkt des sowjetischen Anspruchs auf das Baltikum wurde zu einer Metapher für die gesamtbaltische Forderung nach historischer Gerechtigkeit ${ }^{12}$. Da jedoch die Bewertung der eigenen Geschichte sich nun wieder nach dem in die Vergangenheit projizierten Grad der nationalen Unabhängigkeit und Kultur richtete, hörten die Gemeinsamkeiten der drei Länder hier auf, denn jedes Land suchte nach seiner eigenen Geschichte. In Estland lieferten 1989 drei jüngere Historiker um den späteren Ministerpräsidenten Mart Laar mit ihrer bereits 1983 im Untergrund verfaßten „Heim(at)geschichte" (Kodu lugu) einen kanonischen Schlüsseltext mit vier programmatisch betitelten Oberkapiteln: „Heim und Herd“ (Koda ja kolle), „Untertan im eigenen Haus“ (Käsualuseks omas kojas), „Herr im eigenen Haus" (Oma tuba, oma luba) und „In die Ecke gedrängt" (Nurka surutud) ${ }^{13}$. Rhetorisch war dies nicht nur der

1918/1919 und 1987/1989, in: The Independence of the Baltic States: Origins, Causes, and Consequences. A Comparison of the Crucial Years 1918-1919 and 1990-1991, hrsg. v. Eberbard Demm, Roger Noël, William Urban (Chicago 1996) 131-137, hier 135.

11 Peeter Tulviste, History Taught at School Versus History Discovered at Home: The Case of Estonia, in: European Journal of Psychology of Education 9 (1994) 121-126, hier 125. Vgl. ders., James V. Wertsch, Official and Unofficial Histories: The Case of Estonia, in: Journal of Narrative and Life History 4 (1994) 311-329; ders., Riik raamaturiiulis ehk eesti haritlase koduraamatukogu Nõukogude ajal, in: Raamatu osa Eesti arengus, hrsg. v. Tõnu Tender (Tartu 2001) 125-128.

12 Heino Arumäe, Noch einmal zum sowjetisch-deutschen Nichtangriffspakt, in: HitlerStalin-Pakt 1939. Das Ende Ostmitteleuropas, hrsg. v. E. Oberländer (Frankfurt a. M. 1989) 114-124; Gert von Pistoblkors, Der Hitler-Stalin-Pakt und die Baltischen Staaten, in: ebd. 75-97; Jan Lipinsky, Sechs Jahrzehnte Geheimes Zusatzprotokoll zum Hitler-Stalin-Pakt. Sowjetrussische Historiographie zwischen Leugnung und Wahrheit, in: Osteuropa 50 (2000) 1123-1148; Karsten Brüggemann, Estland im Schicksalsjahr 1940. Neue Quellenpublikationen, in: Nordost-Archiv. Zeitschrift für Kulturgeschichte und Landeskunde 24 (1991) 251268.

13 Mart Laar, Lauri Vabtre, Heiki Valk, Kodu lugu, 2 Bde. (Tallinn 1989). 
Verweis auf die zu Hause (kodus) überlieferte Geschichte, sondern auch ein Rückgriff auf die ersten Gehversuche der estnischen Historiographie am Ende des 19. Jahrhunderts, als der Dorfschullehrer Villem Reiman mit der Metapher der Entwicklung des „estnischen Heims“ (Eesti kodu) die nationale Geschichte popularisierte ${ }^{14}$. Auch wenn Laar sich mittlerweile vorsichtig hiervon distanziert und brav in den Chor derjenigen eingereiht hat, die eine pluralistische Geschichte fordern ${ }^{15}$, bleibt Kodu lugu als Schlüsseltext einer Reaktion auf sowjetische Schemata eine prominente Quelle für das renationalisierte estnische Geschichtsbild der 1980 er Jahre.

In den folgenden Ausführungen wird es nicht nur um inhaltliche Aspekte des Themas Geschichte und Transformation gehen - welche Seiten der eigenen Vergangenheit erfuhren eine Neuinterpretation, welche wurden womöglich weiterhin oder neuerdings tabuisiert -, sondern auch um Fragen der Diskussionskultur: Sind überhaupt schon Ansätze einer pluralistischen Streitlust entstanden, die in die Öffentlichkeit wirken? Wirkt Geschichte überhaupt noch öffentlich? Die institutionelle Umgestaltung der Wissenschaftslandschaft ist zusammenfassend an anderer Stelle behandelt worden ${ }^{16}$. Es sei an dieser Stelle trotzdem kurz darauf hingewiesen, daß es in Estland zeitgleich mit der politischen Wende und den von ihr evozierten Umstrukturierungen einen Generationswechsel unter den führenden Historikern gegeben hat. Zwar ging damit ein Einschnitt in der absoluten Zahl an wissenschaftlichen Mitarbeitern - etwa an dem aus der Trägerschaft der Akademie der Wissenschaften in die Obhut des Bildungsministeriums entlassenen Institut für Geschichte in Tallinn - einher, doch gab es in Estland keine Abwicklung bzw. Evaluation politischer Loyalität oder wissenschaftlicher Kompetenz unter den Historikern. Neben der Abteilung für Geschichte an der Philosophischen Fakultät der Universität Tartu seien als Lehrstätten für Geschichte noch die Pädagogische Universität Tallinn und das private Estnische Humanistische Institut, ebenfalls in Tallinn, erwähnt. Welche Veränderungen in der bislang einseitig auf die Universität Tartu und die diversen Abteilungen des Estnischen Staatsarchivs ausgerichteten historischen Forschung die geplante Zusammenlegung der Tallinner universitären Einrichtungen zu einer Hochschule mit sich bringen wird, wird die Zukunft zeigen ${ }^{17}$.

14 Villem Reiman, Eesti kodu (Jur'ev 1894); vgl. Tït Rosenberg, Ajaloo raiumisest raamatusse: Eesti ajaloo suurest narratiivist, in: Raamatu osa Eesti arengus, hrsg. v. Tõnu Tunder (Tartu 2001) 66-81.

15 Mart Laar, Meie ise ja meie enda lähiajalugu, in: Akadeemia 11 (1999) 2323-2327; vgl. die frühe Kritik bei Tiit Veispak, Ajalooteadusest kui venestusideoloogia kandjast (1944-1952), in: Looming (1990) H. 9, 1260-1268, hier 1267.

${ }_{16}$ Sirje und Jüri Kivimäe, Geschichtsschreibung und Geschichtsforschung in Estland. Zwischenbilanz von 1988-2001, in: Österreichische Osthefte 44 (2002) 159-170; Konrad Maier, Geschichtsschreibung und Geschichtsforschung in Estland. Zwischenbilanz 1988-2001, in: ebd. 171-178.

17 Ebd. Dieser Zusammenschluß ist im Frühjahr 2005 offiziell vollzogen worden. 


\section{Geschichte und ihre Bedeutung zu Beginn des Transformationsprozesses}

Die schon aus der Zwischenkriegszeit bekannte Debatte, ob Geschichte inklusive Landes- oder exklusive Volksgeschichte sei, d.h. ob die Geschichte des Landes, des Staates oder ausschließlich die des eigenen Volks geschrieben werden solle ${ }^{18}$, wurde zunächst meist zugunsten der letzteren Variante entschieden. Vor allem bei den Schulbüchern spielte der Paradigmenwechsel im Geschichtsbild eine signifikante Rolle, da er das Selbstverständnis des neuen Staats im Kern betraf. Daher erklärte der Frühneuzeitprofessor Helmut Pïrimäe 1990 neue Geschichtsbücher zum Beitrag der Historiker zur nationalen Unabhängigkeit ${ }^{19}$. Immerhin stellte der Lüneburger Estland-Experte Konrad Maier in einer Analyse der ersten neuen estnischen Schulbücher fest, daß die estnische nationale Bewegung am Ende des 19. Jahrhunderts „ohne jeglichen nationalistisch gefärbten Unterton“ geschildert und insgesamt mit bemerkenswerter „emotionaler Distanz" geurteilt werde ${ }^{20}$. Trotzdem: Für Historiker, die in ihrer Praxis nie über ihr Fach reflektieren mußten, da dessen Rolle im Sowjetstaat ohnehin klar begrenzt war, lag die Versuchung nahe, die alten Dogmen durch noch ältere zu ersetzen, wovon auch die Schulbücher nicht ganz frei sind21. Der Politologe Rein Ruutsoo hat dieses Dilemma in einem zornigen Beitrag folgendermaßen beschrieben: Das Erbe der Sowjetunion

18 Jüri Kivimäe, Re-writing Estonian History?, in: National History and Identity. Approaches to the Writing of National History in the North-East Baltic Region. Nineteenth and Twentieth Centuries, hrsg. v. Michael Branch (Helsinki 1999) 205-212, hier 210; vgl. Hackmann, Ethnos, und Helme, Historiographie. Neuerdings Veronika Wendland, Volksgeschichte im Baltikum? Historiographien zwischen nationaler Mobilisierung und wissenschaftlicher Innovation in Estland, Lettland und Litauen (1919-1939), in: Volksgeschichten im Europa der Zwischenkriegszeit, hrsg. v. Manfred Hertling (Göttingen 2003) 205-238.

19 Helmut Piirimäe, Some Basic Conceptions of History Teaching in Estonian Schools, in: Geschichtsbild in den Ostseeländern 1990 (Stockholm 1991) 153-160. Das sowjetische Curriculum hatte wenig Platz für nationale Geschichten gelassen, die sowjetische - und das hieß zum großen Teil: die russische - Geschichte hatte Heimatgeschichte zu sein, wobei stets die hervorragenden russisch-estnischen Beziehungen und die positive Rolle Rußlands für Estland betont wurden. Der mittelalterlichen baltischen Geschichte blieb meist nur ein Absatz in einer "Geschichte der UdSSR“. Zu Estland wußten sowjetische Schulbücher ansonsten höchstens zu berichten, daß der spätere sowjetische Staatschef Michail Kalinin einst als Dreher in einer Tallinner Fabrik gearbeitet hatte. Im Lehrplan des Jahres 1988 standen für die Geschichte Estlands nur 50 von 622 Stunden zur Verfügung. Helmut Piirimäe, Die Behandlung der estnischen nationalen Bewegung und der Gründung der Estnischen Republik in den Lehrbüchern während der sowjetischen Okkupation, in: Nationalbewegung und Staatsbildung. Die baltische Region im Schulbuch, hrsg. v. Robert Maier (Studien zur internationalen Schulbuchforschung 85, Frankfurt a. M. 1995) 69-78, hier 71.

20 Konrad Maier, Nationalbewegung und Staatsbildungsprozesse im Spiegel aktueller Schulbücher, in: Nationalbewegung und Staatsbildung. Die baltische Region im Schulbuch, hrsg. v. Robert Maier (Studien zur internationalen Schulbuchforschung 85, Frankfurt a. M. 1995) 79-94, hier $93 \mathrm{f}$. Vgl. auch Kivimäe, Geschichtsforschung, sowie die diesbezüglichen Anmerkungen bei Maier, Geschichtsschreibung.

21 So z. B. Ajalugu. 5 klassile, hrsg. v. Mart Laar u. a. (Tallinn 1997). 
bestehe eben nicht in den verfälschten Fakten allein, sondern vor allem darin, daß der Historiker als Souverän, als Schöpfer einer subjektiven Geschichte ausgelöscht worden sei. Daher rührt auch seine Forderung, Estland brauche viele verschiedene Geschichten ${ }^{22}$.

Ende der 1980er Jahre verlangte das estnische Paradigma jedoch die Abgrenzung von den Schablonen der sowjetischen Historiographie. Grenzen wurden gezogen, um, wie in anderen ehemaligen "Bruderrepubliken" auch, mit ihrer Hilfe die eigene, postsowjetische Identität zu stützen und damit den postkolonialen nation-building Prozeß zu beschleunigen. Graham Smith hat diese Perspektive in einem dreiteiligen Schema von Grenzziehungen „Essentialisierung“ genannt: die Kodifizierung einer ethnischen oder nationalen Gruppe als distinkte, separate „Wir“-Identität ${ }^{23}$. Eng mit der „Essentialisierung“ verbunden, wird in der Perspektive der "Historisierung" die nationale Vergangenheit wiederentdeckt und rehabilitiert. Auch in Estland diente die Renationalisierung der Geschichte der „Auffrischung“ des historischen Gedächtnisses, wobei die Rückkehr der „großen historischen Persönlichkeit" Vorbildcharakter haben und einer vereinfachten Identifikation mit der „eigentlichen“ Geschichte dienen sollte" ${ }^{24}$. Egal ob Helden stilisiert oder Personen in den Kontext gestellt werden: Hierdurch sollte nationale Kontinuität in Form von „traditionalem Erzählen“ erfahrbar gemacht werden ${ }^{25}$. Das öffentliche Verlangen nach unzensierter, d.h. nicht-sowjetischer Information war groß, und man fand sich zwangsläufig beim Erbe der 1930er Jahre wieder. Natürlich war dieses Erbe politisiert, da es ja ebenfalls, um in Smiths Sprache zu bleiben, post-kolonial war. Aber es bediente erfolgreich den Hunger der Bevölkerung nach der "wahrhaften und unverfälschten" Geschichte im Prozeß der DeSowjetisierung. Eine reine Wiederherstellung dieses Erbes war jedoch nicht nur wegen der veränderten Lage in Estland selbst unmöglich, sondern auch aufgrund der politischen Ausrichtung auf eine Demokratie westlichen Musters, als deren vollkommene Verkörperung das „Pätsonia“ der 1930er Jahre nicht gerade gelten konnte ${ }^{26}$.

22 Kommentar von Rein Ruutsoo auf die Frage "Wie schreibt man estnische Geschichte?“ (Kuidas kirjutada eesti ajalugu?), in: Vikerkaar (2000) H. 8-9, 178-190, hier 186-188.

${ }^{23}$ Grabam Smith, Post-colonialism and Borderland Identities, in: Nation-building in the Post-Soviet Borderlands. The Politics of National Identities, hrsg. v. Grabam Smith (Cambridge 1998) 1-20, hier $15 \mathrm{f}$.

24 Paradigmatisch das Bändchen mit dem Titel „Offen und ehrlich über die großen Männer Estlands": Ausalt \& avameelselt Eesti suurmeestest. Johan Laidonerist, Jaan Poskast, Konstantin Pätsist, Jaan Tõnissonist (Tallinn 1990). Auf zahlreiche in den Wendejahren veröffentlichte Reprints von biographischen Arbeiten aus den 1920er und 1930er Jahren sei hier hingewiesen, ohne sie im einzelnen aufzuzählen.

25 Begriffe nach Jörn Rüsen, Historisches Erzählen, in: Handbuch der Geschichtsdidaktik, hrsg. v. Klaus Bergmann u. a. (Seelze-Velber 1992) 44-50, hier 46.

${ }^{26}$ „Pätsonia“ bezeichnet das Regime des autoritär regierenden Präsidenten Konstantin Päts (1934-1940). Zur Einführung in die estnische Geschichte der 1930er Jahre: Georg v. Rauch, Geschichte der baltischen Staaten (München ${ }^{3} 1990$ ); Rein Taagepera, Estonia. Return to Independence (Boulder, Col. 1993) 41-76; Andres Kasekamp, The Radical Right in Interwar 
Tendenzen und Ergebnisse der estnischen Forschung in den 1990er Jahren habe ich ausführlich in einem Beitrag für die Zeitschrift „Osteuropa" referiert ${ }^{27}$. Themen wie die „unbekannte Estnische Republik“, die sowjetische Okkupation und die Deportationen waren in der Sowjetunion entweder nur entstellt behandelbar oder komplett tabuisiert gewesen und bedienten zunächst das öffentliche Interesse, doch hatte niemand Zeit und Geld für fundierte Forschungen. Emotion und Empirie ersetzten Ratio und Methode. Paradigmatisch kann für diese betont nationale Form historischer Publizistik erneut ein Buch des Ministerpräsidenten Mart Laar (1992-1994, 1999-2002) über die sogenannten Waldbrüder erwähnt werden, einem bis dahin nur oral tradierten Thema. Laars Pionierstudie über den bewaffneten Widerstand nach Kriegsende beruhte auf einem oral history-Projekt der späten 1980er Jahre und sang das Heldenlied einer verlorenen Generation bei konsequenter Verweigerung der Täterperspektive ${ }^{28}$. Wie in anderen Bereichen auch, geben neuere Publikationen selbst bei diesem sensiblen Thema ${ }^{29}$ Anlaß zur Hoffnung, daß der „von positivistisch erläuternder Verifikation getragene[...] national-rationale[...] Narrativ", den Sirje und Jüri Kivimäe als charakteristisch für die estnische Historiographie der 1990 er Jahre ansehen ${ }^{30}$, allmählich überwunden wird, bei der jüngeren Generation zumal. Prinzipiell sind die meisten neueren Arbeiten allerdings weiterhin estlandzentrisch, und nur vereinzelt gibt es die Tendenz, über den eigenen Tellerrand hinauszublicken. Noch gibt es auch keinen ernsthaften Versuch, estnische Geschichte unter wissenschaftlichen Anforderungen „neu“ zu schreiben, schon gar nicht mit einer Feder. Auf ein von der Regierung gefördertes diesbezügliches Kollektiv-Projekt der Universität Tartu darf

Estonia (London u. a. 2000); Ago Pajur, Die „Legitimierung“ der Diktatur des Präsidenten Konstantin Päts und die öffentliche Meinung in Estland, in: Autoritäre Regime in Ostmittelund Südosteuropa 1919-1944, hrsg. v. Erwin Oberländer in Zusammenarbeit mit Rolf Abmann, Hans Lemberg und Holm Sundhaussen (Paderborn u. a. 2001) 163-213.

27 Karsten Brüggemann, Von der Renationalisierung zur Demontage nationaler Helden Oder: „Wie schreibt man estnische Geschichte?“, in: Osteuropa 51 (2001) 810-819, hier 813816.

28 Mart Laar, Metsavennad (Tallinn 1993, engl. u. d. Titel „War in the Woods“, Washington DC 1992). Mittlerweile ist das öffentliche Interesse am heroisierten Widerstand zurückgegangen. Kürzlich wurde von Laar beklagt, daß nicht einmal mehr die lokale Presse bereit sei, regionalhistorische Artikel über die Waldbrüder-Guerilla zu publizieren. Mart Laar, Vennad, padrik ja partei. Metsavendlusega tegelejad süüdistavad ühiskonda ignorantsuses, in: Kes-Kus, April 2002. Siehe >http://www.kes-kus.ee/0402/_pealugu.htm< letzter Zugriff Mai 2002. Ob dieser Rückgang des Interesses mit der Lettland betreffenden Vermutung von Ieva Gundare zusammenhängt, daß auf lange Sicht die Identifikation mit den „eigenen“ Verlierern und Opfern für die Identitätssuche in einem unabhängigen Staat eine Last sein kann, vermag ich für Estland nur als Hypothese in den Raum zu stellen. Siehe Ieva Gundare, Overcoming the Legacy of History for Ethnic Integration in Latvia, in: Inter Marium. OnLine Journal 5 (2002), No. 3 >http://sipa.columbia.edu/REGIONAL/ECE/newintermar.html< letzter Zugriff September 2002.

29 Aigi Rabi, 1949. aasta märtsiküüditamine Tartu linnas ja maakonnas (Tartu 1998); vgl. David Feest, Terror und Gewalt auf dem estnischen Dorf, in: Osteuropa 50 (2000) 656-671.

${ }^{30}$ Kivimäe, Geschichtsschreibung. 
man gespannt $\operatorname{sein}^{31}$. Zudem muß man festhalten, daß nach dem Geschichtsboom der Wendejahre historische Themen mittlerweile nur noch selten im Mittelpunkt des öffentlichen Interesses stehen ${ }^{32}$. Dies sollte der Forschung wiederum zunehmend den entpolitisierten Freiraum bieten, die Grundzüge estnischer Geschichte mehr oder weniger unabhängig von einer in der Öffentlichkeit verlangten identitätsstiftenden Rolle zu debattieren ${ }^{33}$.

\section{Zwischen Kontinuität und Dekonstruktion: Wege der Neuorientierung}

Jüri Kivimäe hat sich in einem langen Interview zu grundsätzlichen Problemen der estnischen Historiographie geäußert. Man habe keine ausführliche Historiographiegeschichte und leide unter einem eklatanten Theoriedefizit. Da die Zunft klein sei, und jeder auf seinem Gebiet meist der einzige Spezialist, gäbe es zudem strukturelle Hindernisse für fruchtbare Debatten ${ }^{34}$. In Zusammenhang mit dem eben erwähnten Projekt einer Gesamtdarstellung begann jedoch eine Diskussion über die Frage „Wie schreibt man estnische Geschichte?“, die dank der Zeitschrift des Schriftstellerverbandes „Vikerkaar“ (Regenbogen) auch über die engeren Grenzen der Historikerzunft hinausgetragen wurde. Hierin finden sich nicht nur Kivimäes Äußerungen aus wohlmeinender kanadischer Distanz, sondern auch Ruutsoos zitierte Kritik am sowjetischen Erbe, das sich für ihn schon in der Idee einer vom Staat in Auftrag gegebenen Gesamtdarstellung äußert. Seiner reichlich überpointierten Ansicht nach ist bereits der Gedanke daran, wie man Geschichte schreiben $m u ß$, der Eckpfeiler eines künftigen Konzentrationslagers ${ }^{35}$. Daß Estland viele Geschichten braucht und nicht nur die eine, große, dem Staat gefallende, ist allerdings den meisten Teilnehmern an der Debatte ohnehin klar. Ob postmodern oder postkolonial - die postsowjetische Historiographie Estlands hat in der Perspektive ihrer Produzenten in erster Linie pluralistisch zu sein und damit posttotalitär ${ }^{36}$.

31 Vgl. die Ankündigung im Kommentar von Tiit Rosenberg auf die Frage "Wie schreibt man estnische Geschichte?", in: Kuidas kirjutada $185 \mathrm{f}$. Als Fortsetzung der in Anm. 9 genannten "Eesti ajalugu“ zum 18. Jh. bislang erschienen: Põhjasõjast pärisorjuse kaotamiseni, Eesti ajalugu, Bd. 4, hrsg. v. Mati Laur, Sulev Vabtre (Tartu 2003).

32 Gregory Feldman, Shifting the Perspective on Identity Discourse in Estonia, in: Journal of Baltic Studies 31 (2000) 406-428. Auf das Thema „Estland und der Holocaust“ , das im Sommer 2002 in der Presse debattiert wurde, wird unten eingegangen.

$33 \mathrm{Vgl}$. Marek Tamm, Milleks on olemas ajaloolased?, in: Eesti Ekspress, Areen, 8. 12. 2004. Die Debatten, die 2004/05 um die Ereignisse des Jahres 1944 kreisten und in denen zum Teil lautstark die Forderung nach einer nationalen Sichtweise der Historiker erhoben wurde, müssen hier leider unberücksichtigt bleiben.

34 Vestlus Jüri Kivimäega, in: Vikerkaar (2000) H. 8-9, 124-136.

35 Kommentar von Rein Ruutsoo auf die Frage "Wie schreibt man estnische Geschichte?", in: Kuidas kirjutada 186-188.

36 Ausführlich referiert bei Brüggemann, Renationalisierung 819. 
Dabei geht das Interesse in Estland über die Rekonstruktion von Geschichte, über „Essentialisierung" und „Historisierung" von Fakten hinaus. Interessanterweise hat die Lust an der Dekonstruktion nationaler Mythen im Smith'schen Schema der post-sowjetischen Länder als post-koloniale Gesellschaften keinen Platz - sie erfreut sich in Estland jedoch einer für die Transformationsländer wohl eher ungewöhnlichen Popularität. Es ist dabei nicht unerheblich, daß der Anstoß hierzu in Estland von außerhalb der Zunft kam - von dem Journalisten Andrei Hvostov und dem Literaturwissenschaftler und Germanisten Jaan Undusk ${ }^{37}$. Undusks grundsätzliche Überlegungen zum Mythos der 700 Jahre Sklaverei unter deutschbaltischer Herrschaft und seine, wie er es nennt, „metahistorischen Gesten " in der Rhetorik der Historiker ${ }^{38}$ sind ein Versuch, nicht nur die traditionelle deutschsprachige Forschung einer kritischen Analyse ihrer Sprache zu unterziehen, sondern auch estnische Geschichte als Regionalgeschichte zu homogenisieren. Allerdings kann auch die bewußte Zerstörung von identitätsstiftenden $\mathrm{My}$ then neue (bzw. alte) Paradigmen hervorzaubern, zuweilen geschieht auch das völlig bewußt ${ }^{39}$, zuweilen mit Hilfe verborgener Narrative. Tatsächlich ist bei Undusks anregenden Überlegungen zumindest eine Variante von Smiths dritter Perspektive der Konstruktion von post-kolonialer Identität feststellbar: eine „Totalisierung" von Grenzen und Differenzen - durch die Aufhebung von anderen ${ }^{40}$.

In einem Artikel über die kanonischen Möglichkeiten, die Geschichte der Esten zu schreiben, wies Undusk die Absicht einer politisierten nationalen Geschichtsschreibung, über die eine historische „Wahrheit“ Kontinuität und Identität stiften zu wollen, souverän zurück: „[...] if we speak [...] about the canonical ways of narrating Estonian history [...] we speak about the generally approved ways of lying in Estonian historiography. " 41 In seinen historiographiegeschichtlichen Arbeiten über das „estnische“ und das „deutschbaltische“ Paradigma führt Undusk den Begriff der maiskondlik ajalugu ein, einer Geschichte der "Landschaft" im administrativen Sinne, die in seinen Worten eine Geschichte bezeichnet, „die nicht von einem nationalzentrierten Prinzip ausgeht, sondern von etwas, das man als

37 Paradigmatisch für die Lust an der Dekonstruktion nationaler Mythen: Andrei Hvostov, Mõtteline Eesti (Tallinn 1999); Jaan Undusk, Canonical Patterns of Narrating History. In Search of a Hidden Rhetoric, in: Literatur und nationale Identität II. Themen des literarischen Nationalismus und der nationalen Literatur im Ostseeraum, hrsg. v. Yrjö Varpio, Maria Zadencka (Tampere 1999) 5-13; vgl. aber auch schon Jansen, Hajamõtteid 35-41.

38 Jaan Undusk, Ajalootõde ja metahistoorilised žestid. Eesti ajaloo mitmest moraalist, in: Tuna. Ajalookultuuri ajakiri (2000) H. 2, 114-130.

39 Vgl. z. B. Andrei Hvostovs Bekenntnis, er wolle den Mythos der "guten deutschen Zeit" schaffen. Andrei Hvostov, Mart Laar, Harri Tiido, Möttevahetus, in: Eesti identiteet ja iseseisvus, hrsg. v. A. Berticau (Tallinn 2001) 44-54.

$40 \mathrm{Vgl}$. hierzu meine Antwort auf Undusk, Ajalootõde: Karsten Brüggemann, Rahvusliku vaenlasekuju demontaažist ehk Carl Schirren kui Eesti iseseisvuse rajaja? Märkusi Jaan Unduski „metahistooriliste žestide“ kohta, in: Tuna, Ajalookultuuri ajakiri (2002) H. 3, 93-99, sowie Undusks Antwort: Jaan Undusk, Eesti ajaloo kotkaperspektiivist. Minu vaidlus Brüggemanniga, in: ebd. 99-116.

41 Undusk, Canonical Patterns 7. 
geopolitische oder geokulturelle Mentalität bezeichnen kann“42. Zu Recht hält Undusk seine These in der Perspektive der ethnozentrischen Historiographie für „ketzerisch“: Nicht mehr das Volk oder die Nation seien Konstanten der historischen Entwicklung, sondern eine, wie er selbst zugibt, schwer greifbare „geokulturelle Mentalität ${ }^{* 43}$.

Undusk provoziert tradierte estnische Überzeugungen jedoch noch weiter. Sein regionalbezogenes, Lettland miteinbeziehendes Konstrukt steht zum national konnotierten estnischen Paradigma der 1930er Jahre im krassen Widerspruch, wenn er behauptet, daß nicht nur die Esten selbst für ihre Unabhängigkeit gekämpft hätten. Undusks vornationale „geokulturelle Mentalität“ erlaubt es ihm interessanterweise, auch jeden Vorkämpfer für die deutsche bzw. deutschbaltische Sache in den Ostseeprovinzen zum Helden der estnischen, nein, besser, der regionalen Sache der „Baltischen Autonomie“ zu machen. Selbst der deutschbaltische Historiker Carl Schirren wird in dieser Perspektive dank seiner Verteidigung der lokalen Sprache - wohlgemerkt der deutschen - zu einem Mitkämpfer der estnischen nationalen Bewegung. Und Schirrens für das deutschbaltische Paradigma so eminent bedeutungsvolle "Livländische Antwort an Herrn Jurij Samarin“ von 1869 kann plötzlich als Paralleltext zu den „Vaterländischen Reden“ (Isamaa kõned) Carl Robert Jakobsons gelten ${ }^{44}$. Ein (ursprünglich deutsch-) baltischer Regionalismus wird in dieser Perspektive zur Stütze der historischen Kontinuität des Landes bis heute. Fragt man sich, was die von Undusk thematisierte deutsch-estnische bzw. -lettische „Schicksalsgemeinschaft" letztlich zusammenhält, kommt dem Betrachter von außen sofort der aufgrund der gemeinsamen ngeokulturellen Mentalität “ quasi „natürliche“ Antagonismus zu Rußland als Schlüsselfaktor der Region in den Sinn. Hier dürfte also Undusks eigener „verborgener Narrativ“ stecken: Die deutschen Kolonisatoren des Landes haben sich im Interesse der regionalen Autonomie gegen den imperial other zur Wehr gesetzt und damit in weiter historischer Perspektive auch die estnische Sache vorangebracht.

Letztlich dekonstruiert Undusk nichts weniger als die jahrhundertealte „natürliche" estnische Feindschaft gegenüber den Deutschen bzw. Deutschbalten, die noch die Staatsgründung 1918/20 geprägt hatte, und aktiviert die aktuelle Gegnerschaft gegen den russischen Osten, die der Wiedererlangung der Unabhängigkeit 1990/91 zugrunde lag. Und tatsächlich kann es der estnischen Geschichtsbetrachtung heute nicht mehr um das Abschütteln des deutschen Erbes gehen, im Gegenteil: Angesichts der Integration in die westeuropäischen Sicherheits- und Wirtschaftsstrukturen erscheint ein historisch konstruierter Gegensatz zu den Deutschen sogar als kontraproduktiv, schließlich ist an deren kulturellen Einfluß und dem ihnen zu verdankenden Einbezug der Esten in den protestantischen - und damit „europäischen“ - Raum ja nicht zu rütteln ${ }^{45}$. Der vielzitierte „Weg nach

42 Kommentar von Jaan Undusk auf die Frage „Wie schreibt man estnische Geschichte?“, in: Kuidas kirjutada 188-190, hier 188.

43 Undusk, Ajalootõde 128.

44 Undusk, Ajalootõde 129.

$45 \mathrm{Vgl}$. die Debatte um die Einführung des höchsten estnischen Staatsordens, des Marien- 
Europa" kommt in Est- und Lettland idealerweise um den Einfluß der deutschen Kultur in Baltikum nicht herum. Darüber hinaus war der Mythos der „700 Jahre Sklaverei" aber auch ein identitätsstiftender Teil der sowjetischen Mythologie, schließlich stand die sowjetische Historiographie im Punkt der Deutschfeindlichkeit der nationalen estnischen vor 1940 in nichts nach ${ }^{46}$. Die sowjetische Wirklichkeit, d.h. die russisch-imperiale Kontinuität, sollte vor dem Hintergrund der jahrhundertlangen Unterdrückung durch die Deutschbalten im hellsten Licht leuchten. Indem man sich heute diesem Konzept gegenüber kritisch zeigt - und Undusk ist ja bei weitem nicht der erste, der den deutschbaltischen Einfluß auf die Geschichte der Esten und Letten mit guten Gründen rehabilitiert ${ }^{47}$-, wird eben auch ein Teil des sowjetischen Erbes abgelegt.

Ob Dekonstruktion alter Mythen oder Suche nach neuen Perspektiven: Die Wissenschaft steht im estnischen öffentlichen Diskurs nicht allein. Eine Neupositionierung im Sinne eines new mapping Estlands in Europa ist auch das Ziel einiger Politiker ${ }^{48}$. Schon der Begriff des „Baltikum“ und seine Konnotationen bereiten experimentierfreudigen Geistern Unbehagen, gehören doch im heutigen Verständnis des Begriffs nur ehemalige Sowjetrepubliken dazu. Der ehemalige AuBenminister Toomas H. Ilves wollte die verfluchte „Baltic connection“ am liebsten ganz loswerden: „My goal as foreign minister was to separate Estonia from being a Baltic state. [...] I don't think Estonia is a Baltic state." Sein Land sei vielmehr ein postkommunistisches nordisches, skandinavisches Land: „it's strictly Nordic." Ilves führte in diesem Zusammenhang das Beispiel Finnlands an, das es geschafft habe, sein Image als baltischer Staat seit dem Zweiten Weltkrieg in dasjenige eines skandinavischen Landes zu wandeln: „Why should Finland be more of a Scandinavian country than Estonia? [...] That's why I try to sell Estonia as the

kreuzes (Maajamaa rist), dessen katholische Konnotation Verwirrung in der Öffentlichkeit hervorrief: Mirkko Lagerspetz, The Cross of Virgin Mary's Land: A Study in the Construction of Estonia's „Return to Europe“, in: Idäntutkimus. The Finnish Review of East European Studies 6 (1999). Special issue: Images of the Past in Post-Socialist Politics 17-28; Brïggemann, Renationalisierung $816 \mathrm{f}$.

46 Toivo U. Raun, The Image of the Baltic German Elites in Twentieth-century Estonian Historiography: The 1930s vs. the 1970s, in: Journal of Baltic Studies 30 (1999) 338-351, hier 348.

47 Sukzessive begann dieser Prozeß der Emanzipation von sowjetischen Stereotypen bereits vor der Perestroika. Das Ergebnis waren dann die zu Beginn der 1990er Jahre erschienenen Bestandsaufnahmen. Vgl. z.B. Rein Helme, Die Deutschen in der Geschichte Estlands, in: Nordost-Archiv N.F. 1 (1992) 41-58; Sirje Kivimäe, Estland ohne die Deutschbalten, in: Die Deutschbalten, hrsg. v. Wilfried Schlau (München 1995) 136-53. Jüngst wurde der 750. Geburtstag der mittlerweile in der Bundesrepublik residierenden estländischen Ritterschaft, der in Tallinn begangen wurde, in der estnischen Presse zum "Jahrestag des estnischen Parlamentarismus“ erklärt. Schließlich handele es sich hier um „Estlands erste Institution der europäischen Politik“. Eerik-Niiles Kross, Eesti poliitika 750, in: Eesti Päevaleht, 10. September 2002.

48 Hierzu siehe auch Karsten Brüggemann, Leaving the „Baltic“ States and „Welcome to Estonia“: Re-regionalizing Estonian Identity, in: European Review of History 10 (2003) 343-360 (Topical Issue „Geschichtsregionen“: Concept and Critique, ed. by Stefan Troebst). 
only Nordic, the only post-communist Nordic country. "49 Daher versteht sich auch seine Empfehlung, Touristen sollten doch lieber eine CD des estnischen Komponisten Arvo Pärt als Souvenir erstehen und nicht die (schon zu Sowjetzeiten üblichen) „handmade“ Löffelchen und Tellerchen, als Wunsch nach einem neuen, zeitgemäßen Bild von Estonia im Ausland.

Das Spiel mit den Traditionen auf der Suche nach einer neuen, weniger sowjetisch konnotierten Identität - unter dem label „selling Estonia“ - geht derweil munter weiter. Im Herbst 2001 machte der Kolumnist Eerik-Niiles Kross, der wie viele Kollegen und Politiker seines Landes Historiker ist, den Vorschlag, den im Ausland gebräuchlichen Namen Estonia durch Estland zu ersetzen ${ }^{50}$, und Kaarel Tarand, damals Direktor des Pressebüros der Regierung, machte im Anschluß daran mit der Idee Furore, die traditionelle blau-schwarz-weiße Staatsfahne durch ein skandinavisches Kreuz in denselben Farben zu ersetzen ${ }^{51}$. Mit der neuen Form nationaler Symbolik sollte nach Meinung der beiden Tabubrecher eine positive Identifikation Estlands im Ausland mit den „sympathischen" Nordeuropäern, die eine Kreuzfahne ihr eigen nennen, bzw. mit den „-ländern“ Westeuropas evoziert werden. Es war keine große Überraschung, daß diese Vorschläge in verschiedenen Abstimmungen in der Presse und im Internet mit überwältigender Mehrheit abgelehnt wurden; rationale Kommentatoren fürchteten unter anderem nicht zu Unrecht, sich vor allem in Skandinavien selbst lächerlich zu machen, da eine Kreuzfahne die eigene Gesellschaft kaum „skandinavisieren" werde ${ }^{52}$. Bemerkenswert ist jedoch die in den Weiten des ehemaligen „Ostens" selten anzutreffende Bereitschaft estnischer Intellektueller, die tradierte nationale Symbolik, mit der die Republik der Zwischenkriegszeit verbunden ist, mit der "ganz Estland“ neben seinen Nachbarn am 23. August 1989 auf der Straße von Tallinn nach Vilnius stand, und mit der schließlich die Unabhängigkeit zurückgewonnen wurde, mithin das, was anderswo als sakrosankte nationale Ikonographie gilt, auf dem Altar eines modernisierten Selbstbildes zu opfern - und sei es nur als provokantes Denkspiel.

Solche und ähnliche "gediegenen Haarspaltereien“, die schon die pfiffige Werbebroschüre des estnischen Pavillons auf der EXPO in Hannover als so typisch für die „skeptische Natur“ der Bewohner dieses Landes bezeichnet hat ${ }^{53}$, ändern allerdings wenig daran, daß Mythen beständig bleiben und Ketzerei noch immer von der Öffentlichkeit bestraft wird, vor allem wenn es um Identifikationsfiguren der eigenen Geschichte geht ${ }^{54}$. Typisches Beispiel war im Herbst 1999 die Debatte um Konstantin Päts, den seit 1934 autoritär regierenden Präsidenten der Zwi-

$49 \mathrm{Im}$ Internet unter: >http://www.balticsww.com/news/features/selling_estonia2.htm< letzter Zugriff Mai 2002; vgl. Toomas H. Ilves, Põhjamaine riik ja inimene, in: Luup 2001, Nr. 1 (128).

50 Eerik-Niiles Kross, Estland, Estland über alles, in: Eesti Päevaleht, 12. November 2001.

51 Kaarel Tarand, Lippude vahetusel, in: Eesti Päevaleht, 3. Dezember 2001.

52 Rahvas eelistab Estoniat ja trikoloori, in: Postimees, 21. Januar 2002; vgl. Aadu Must, Lipu, vapi ja hümni otsingust, in: Postimees, 15. Dezember 2002.

5312 Fragen über Estland (Tallinn 2001) 12.

54 Intervjuu: Vestlus Jüri Kivimäega $131 \mathrm{f}$. 
schenkriegszeit, die schnell in den Medien auf die Formel „Staatsvater oder Verräter?" gebracht wurde. Ein jüngerer Spezialist für die Außenpolitik Estlands hatte in Moskauer Archiven Dokumente gefunden, die das populäre Bild des patriarchalischen Landesvaters Päts empfindlich verdüsterten ${ }^{55}$. Magnus Ilmjärvs zum Teil überpointierte Demontage dieses nationalen Helden ${ }^{56}$ löste eine emotional geführte Debatte in der Presse aus, an der ein Riß durch die Generationen bemerkenswert war, denn vor allem ältere Menschen reagierten darauf mit Verdächtigungen: Selbst der bekannte Schriftsteller Jaan Kross („Das Leben des Balthasar Rüssow“, „Der Verrückte des Zaren“) sprach von Ilmjärvs „Geldgebern“ und fragte nach, in wessen Interesse dieser denn handele ${ }^{57}$.

Trotz der Beteiligung von Historikern an der Debatte kam es jedoch nicht zu einem Historikerstreit, zu stark hatte bereits zuvor das populäre positive Image des autoritären Präsidenten aufgrund neuerer Forschungen gelitten ${ }^{58}$. Aber das Thema Päts erregt weiter die Gemüter: Ende Mai 2002 wurde ein reißerisches Interview mit dem Leiter des Finnischen Instituts in Tallinn, Martti Turtola, publiziert, der ein Buch vorbereitet, in dem er Päts als "Spieler" vorführen möchte ${ }^{59}$. Es entbehrte nicht einer gewissen Pikanterie, daß ausgerechnet Mati Graf, ein verdienter sowjetestnischer Historiker und Spezialist für die, wie es damals hieß, „bürgerliche Diktatur", in einer Replik mit Vorwürfen konterte, die darin gipfelten, daß er den finnischen Kollegen als "entweder Dilettant oder geisteskrank“ bezeichnete ${ }^{60}$. Auch hier fehlten Argumente, so daß eine fruchtbare Diskussion unter Kollegen - diesmal wohl durchaus aus verständlichen Gründen - nicht zustande kam. Ein Wiederaufleben der öffentlichen Debatte blieb nach dem Erscheinen des Buches in Estland ebenfalls aus ${ }^{61}$.

\section{Die importierte Debatte um den Holocaust in Estland}

Von außen mag man sich in Estland - wen wundert's - nichts sagen lassen, wenn es um umstrittene Episoden der eigenen Geschichte geht. Das Thema des Mordes an Juden auf estnischem Boden oder durch Esten im Verlauf des Zweiten Weltkriegs stellt hier keine Ausnahme dar. Die historische Opferrolle ist nach wie vor klein-

55 Vom Tanz mit des Teufels Großmutter. Die estnische Debatte um die Zusammenarbeit von Präsident Konstantin Päts mit der Sowjetunion, zusammengestellt von Ulrike Plath und Karsten Brüggemann, in: Osteuropa 50 (2000) A 329-A 339.

56 Magnus Ilmjärv, Konstantin Päts ja Nõukogude Liidu Tallinna saatkond: aastad 19251934, in: Acta Historica Tallinnensia 3 (1999) 156-223.

57 Vom Tanz mit des Teufels Großmutter, A 334, A 336.

58 Vgl. auch: Konstantin Pätsi tegevusest. Artiklite kogumik, hrsg. v. Küllo Arjakas (Tallinn 2002).

59 Martti Turtola, Konstantin Päts oli mängur, in: SL-Õhtuleht, 11. Mai 2002, $16 \mathrm{f}$.

60 Mati Graf, Pätsi uurija Turttola - diletant või vaimuhaige?, in: SL-Ôtuleht, 18. Mai 2001,7.

61 Martti Turtola, President Konstantin Päts. Eesti ja Soome teed (Tallinn 2003). 
ster gemeinsamer Nenner, zumindest in der Öffentlichkeit ${ }^{62}$. Sie besagt, daß erstens Esten zumeist nur auf deutschen Befehl an Erschießungen beteiligt waren, und zweitens unter der ein halbes Jahrhundert währenden sowjetischen Besatzung estnischen Staatsbürgern weitaus mehr Leid zugefügt worden ist. Während in Westeuropa die Behandlung kommunistischer Verbrechen immer noch stark politisiert ist - wie zuletzt die Debatte um das „Schwarzbuch des Kommunismus“ gezeigt hat - muß man den Rekurs auf sie in Osteuropa als unbestrittenes konstitutives Element ansehen, auf dem die Identität der jungen Staaten zumindest zum Teil gründet. Fast reflexartig evoziert daher jede Form von Forderung nach Aufklärung über die „dunklen Seiten der Geschichte" von außen nicht nur in Estland die Gegenforderung: Akzeptiert endlich, daß für uns die roten Verbrechen schlimmer waren als die braunen ${ }^{63}$. Daß zwangsläufig auf beiden Seiten Esten beteiligt waren, macht die Aufklärungsarbeit nicht leichter. Und im Westen wird gern übersehen, welche Tragödie sich im Baltikum zwischen 1939 und 1944 abgespielt hat, die vor allem von Veteranen aus dem Kreis der antisowjetischen Dissidenz und von der Erlebnisgeneration immer noch als sowjetischer Genozid an den Esten, Letten und Litauern bezeichnet wird. Andererseits ist auch klar, daß angesichts der nachweisbaren eigenen Mittäterschaft am Judenmord - ob auf deutschen Befehl oder nicht - die identitätsstiftende historische Opferrolle bedroht ist. Angriffe auf den schleppenden Prozeß der „Vergangenheitsbewältigung “, die nur allzu leicht als Kollektivanklage gewertet werden, schaffen eine Belagerungsmentalität, die sich hinter den alten Legenden verschanzt. Es muß auch im Westen akzeptiert werden, daß der stalinistische Terror für die Esten, Letten und Litauer wie der Holocaust für die Juden zu einem wesentlichen Teil der eigenen Identität geworden ist ${ }^{64}$. Diese simple Differenzierung erscheint notwendig, auch um anzudeuten, wie wesentlich eine gefestigte eigene Identität ist, bevor sie die eigene Täterrolle annehmen kann - man denke nur an das deutsche Beispiel.

Die Untersuchung der Zeit der deutschen Besatzung, die von einer internationalen Öffentlichkeit vehement eingefordert wird, war bis vor kurzem in Estland tatsächlich ein Desiderat der Forschung ${ }^{65}$. Hier ist die von Präsident Lennart Meri

62 Aber auch in den Geschichtsbüchern: In einem 1999 in mindestens sechs Sprachen erschienenen Band über die Geschichte aller drei Staaten wird die eigene Beteiligung am Holocaust verschwiegen. Die Judenvernichtung wird zwar mit Zahlen belegt, doch seien die Pogrome von den Deutschen organisiert gewesen und hätten nicht den erwünschten Erfolg in der Bevölkerung gehabt. The History of the Baltic Countries, hrsg. v. Zigmatas Kiaupa, Ain Mäesalu, Ago Pajur, Gvido Straube (Tallinn 1999) 174.

63 Hier sei auf den Eklat während der Leipziger Buchmesse 2004 erinnert. Siehe Joachim Güntner, Unkenntnis und ungleiches Gedenken. Gulag und Holocaust - Nachbetrachtungen zum Eklat von Leipzig, in: Neue Züricher Zeitung v. 3. 4. 2004.

64 Anton Weiss-Wendt, Mida tähendab meile holocaust? Võrdlevalt Ameerikast ja Eestist, in: Vikerkaar (2001) H. 8-9, 112-123, hier 122.

65 Vgl. aber Eugenia Gurin-Loov, Suur häving. Eesti juutide katastroof 1941 (Tallinn 1994); dies., Verfolgung der Juden in Estland (1941-1944). Rettungsversuche und Hilfe, in: Solidarität und Hilfe für Juden während der NS-Zeit. Regionalstudien II: Ukraine, Frankreich, Böhmen und Mähren, Österreich, Lettland, Litauen, Estland, hrsg. v. Wolfgang Benz und 
1998 eingerichtete Kommission unter Leitung des finnischen Historikers und Diplomaten Max Jakobson in der Verantwortung, Ergebnisse vorzulegen ${ }^{66}$. Ein erster Band ist 2002 erschienen, in dem die Menschenverluste aus der Zeit der deutschen Okkupation dokumentiert wurden ${ }^{67}$. Für die nächste Zukunft ist ein Sammelband zu den Jahren 1941-44 angekündigt, der von dem aus Kanada stammenden Direktor des Instituts für Außenpolitik und Professor an der Universität Tartu, Andres Kasekamp, herausgegeben wird. Einige grundsätzliche Aufsätze über den Mord an den estnischen Juden, die Lager auf estnischem Boden und den Einsatz von Esten in verschiedenen bewaffneten Einheiten des Dritten Reiches sind in einem inzwischen vergriffenen Heft des erwähnten Organs des Schriftstellerverbands „Vikerkaar“ im Herbst 2001 erschienen ${ }^{68}$.

Unstrittig ist dieser Anfang in der Erforschung der Jahre 1941-1944 Folge der vehementen Einmischung von außen. Wichtig wird dabei in erster Linie sein, wie die neuen Forschungsergebnisse an die eigene Öffentlichkeit vermittelt werden. Eine denkbar ungünstige Ausgangsposition hierfür schufen 2001/02 jedoch die Untersuchungen des Simon-Wiesenthal-Zentrums. Seinem Vertreter Efraim Zuroff, der von dem bekannten Schriftsteller Jaan Kaplinski nicht ohne Grund zu einem der unpopulärsten Menschen in Estland erklärt worden ist ${ }^{69}$, wäre etwas mehr Sensibilität für die Situation in den baltischen Ländern und den Umgang mit ihrer Vergangenheit zu wünschen. Die Hartnäckigkeit und Engstirnigkeit, mit der Zuroff in regelmäßigen Abständen die Verurteilung von vermeintlichen estnischen (lettischen, litauischen) NS-Schergen fordert, sucht ihresgleichen, schon weil Zuroff den historischen Kontext der Jahre 1940-1945 komplett auszublenden scheint und bislang nur wenig beweiskräftiges Material vorlegen konnte ${ }^{70}$. Nach ersten publizistischen Debatten im Jahre 1998 dominierte das Thema des

Juliane Wetzel (Solidarität und Hilfe 2, Berlin 1998) 295-307. Zu ihr Weiss-Wendt, Mida tähendab 121.

$66 \mathrm{Vgl}$. den Forschungsbericht der Kommission im Internet $>$ http://www.historycommission.ee< sowie den polemischen Meinungsaustausch zwischen Anton Weiss-Wendt und Toomas Hiio in: Vikerkaar (2002) H. 8-9, 220-224.

67 Eesti rahvastikukaotused II/1. Saksa okupatsioon 1941-1944. Hukatud ja vangistuses hukkunud. Population Losses in Estonia II/1. German Occupation 1941-1944. Executed and died in prison, hrsg. v. Indrek Paavle (Tartu 2002).

68 Meelis Maripuu, Eesti juutide holokaust ja eestlased, in: Vikerkaar (2002) H. 8-9, 135-146; Ribo Västrik, Klooga koonduslaager - Vaivara süsteemi koletu lõpp, in: ebd. 147-155; Toomas Hiio, Eesti üksused kolmanda reich'i relvajõududes, in: ebd. 156-179. Im selben Heft erschienen ins Estnische übersetzte Texte von Raul Hilberg, Jorge Semprun, Primo Levi, Elie Wiesel sowie einige Gedichte von Paul Celan und Auszüge aus den Tagebüchern von Victor Klemperer. Ein Beitrag des Schriftstellers Jaan Kaplinski mit dem provozierenden Titel „Mida need juudid ometi tahavad?" (Was wollen diese Juden eigentlich?) setzt sich mit antijüdischen Stimmungen in Estland auseinander (ebd. 214-217).

69 Kaplinski, Mida need juudid ometi tahavad 217.

70 Eine Übersicht über Zuroffs Aktivitäten aus Anlaß der Bitte des Wiesenthal-Zentrums an die Regierung Venezuelas, u.a. den damals 81-jährigen Harry Männil auszuliefern, bietet der Artikel: Efraim Zuroff: natside kaastööline Harry Männil tuleb välja anda, in: Postimees, 20. März 2001. Ein vor Gericht verwertbarer Beweis für Männils Beteiligung an der Erschießung von Juden konnte bislang nicht erbracht werden. 
estnischen Umgangs mit der Zeit der NS-Besatzung die Gazetten auch im Sommer 2002, nachdem Zuroff im Mai prominente Unterstützung vom neuen Tallinner US-Botschafter Joseph DeThomas erhalten hatte. Dieser rief mit einem Artikel unter dem Titel "Estland verschweigt den Holocaust" Entrüstung hervor, da er forderte, die Esten sollten wie andere Völker Europas auch den Holocaust als Teil ihrer Geschichte akzeptieren - etwa wie die Deutschen? - und ihre Politiker sich an den jährlichen internationalen Gedenkfeierlichkeiten beteiligen ${ }^{71}$. Kasekamp wies vermittelnd darauf hin, daß der Botschafter die Regierung in erster Linie habe warnen wollen, da der US-Senat im Falle der Aufnahme Estlands in die NATO in jedem Fall Stellungnahmen zum Thema Holocaust aus Tallinn erwarte ${ }^{72}$. Die allgemeine Reaktion in der Presse auf die Vorwürfe war dann jedoch weniger polemisch, als vielleicht zunächst zu erwarten war, aber auch selbstbewußt: Der Botschafter solle sich besser informieren, bevor er sich in die inneren Angelegenheiten Estlands einmische, er habe wohl übersehen, daß sich Präsident Lennart Meri bereits 1994 für die Verbrechen gegen die Juden auf estnischem Boden entschuldigt habe ${ }^{73}$. Natürlich müsse im Bereich der Schulbildung oder bei der Errichtung von Gedenkstätten mehr getan werden, doch sei der ebenfalls von DeThomas im Fahrwasser Zuroffs erhobene Vorwurf, Estland habe nicht einen Nazi-Schergen verurteilt, ungerecht, da erstens das KGB in dieser Hinsicht sehr fleißig gewesen sei und zweitens nach offiziellen Angaben der staatlichen Behörden kein Täter mehr auf estnischem Boden lebe ${ }^{74}$. Auch Max Jakobson wurde mit dem Vorwurf zitiert, daß der Botschafter wohl den Arbeitsbericht der Präsidenten-Kommission nicht gelesen habe ${ }^{75}$. Kolumnist Kross gab seinerseits zu, daß Estland unglaubwürdig erscheine, wenn es die moralische Verantwortung für die NKVD-Opfer anerkenne, diejenige gegenüber den NS-Opfern hingegen ablehne. Allerdings sei der 14. Juni, der Jahrestag der sowjetischen Deportationen von 1941, der in Estland als Gedenktag für alle Opfer fremder Gewaltherrschaft begangen wird, für die Esten weitaus wichtiger ${ }^{76}$. Süffisant wies Kross am Ende seines Beitrags darauf hin, daß noch nie ein US-Botschafter an diesem Tage einen Kranz niedergelegt hätte: „Hoffentlich bedeutet die Aktivität des neuen Gesandten in Fragen der Erinnerung an die Grausamkeiten der Geschichte, daß wir jetzt auch ihn dort erwarten können. " 77 Daß De'Thomas am Deportationstag tatsächlich einen Kranz niederlegte ${ }^{78}$, zeigte immerhin, daß die estnische Presse in der

71 Joseph M. DeThomas, Eesti vaikib holokaustist, in: Eesti Päevaleht, 28. Mai 2002.

72 USA-suursaadik hoiatas Eestit Senati võimalike küsimuste eest, in: Postimees, 29. Mai 2002.

73 Anneli Ammas, USA saadik sekkub Eesti ajalukku, in: Eesti Päevaleht, 28. Mai 2002; vgl. Jubtkiri, ebd.; Suursaadiku mure, in: Postimees, 29. Mai 2002; Erkki Babovski, Holokaust välispoliitika vankri eest, in: Postimees, 29. Mai 2002; Enn Tarto, Eestlased ei tohi lasta end provotseerida, in: Postimees, 30. Mai 2002.

$74 \mathrm{Kapol}$ pole infot Eesti natside kohta, in: Postimees, 29. Mai 2002.

75 Ammas, USA saadik.

76 Dieses Argument nutzt auch Weiss-Wendt, Mida tähendab 122.

77 Eerik-Niiles Kross, Holokaust kui küpsuseksam, in: Eesti Päevaleht, 30. Mai 2002.

78 USA suursaadik tõi leinapärja, in: Postimees, 15. Juni 2002. 
US-Botschaft rezipiert wird - diese Geste gab die Initiative in dieser Frage jedoch wieder an die Esten zurück. Inzwischen ist hier der 27. Januar zum Gedenktag erklärt worden, der vor allem in den Schulen begangen werden soll.

Vor diesem Hintergrund haben der „Pressekrieg“ um Zuroff, seine Anklagen und die Aktion „last chance“, die Auslobung von 10000 Dollar für jeden Hinweis, der zur Ergreifung von estnischen, lettischen oder litauischen "Judenmördern“ führt ${ }^{79}$, die Stimmung im nachrichtenarmen Sommerloch angeheizt. Zum Teil gibt sich die estnische Presse mittlerweile selbst Mühe, Zuroff Arbeit abzunehmen und estnische NS-Täter aufzuspüren ${ }^{80}$. Es bleibt insgesamt mit der einflußreichen Tageszeitung "Postimees" zu hoffen, daß die jeweils "eingekapselten“, in Osteuropa auf Stalins, in Westeuropa auf Hitlers Verbrechen konzentrierten Geschichtsverständnisse sich eines Tages füreinander öffnen werden, so daß auch Zuroff zu einem Verwandten im Geiste werden könne ${ }^{81}$. Daß diese mediale Skandalfigur sich Anfang August 2002 einem online-Interview des „Eesti Päevaleht“ stellte, an dessen Ende er seine Position zu verdeutlichen suchte, war immerhin ein Schritt zum Dialog. Doch solange Zuroff versucht, seine Aktivität nur damit zu rechtfertigen, daß der Holocaust an den Juden „far worse“ gewesen sei als alles, was den Esten angetan worden ist ${ }^{82}$, wird er wenig Anhänger finden, und es kann leider auch

79 Im September 2002 teilte das Wiesenthal-Zentrum mit, daß sich 17 Menschen in den drei baltischen Republiken auf diesen Aufruf hin gemeldet und 51 Namen, davon 47 litauische, drei estnische und einen lettischen, genannt hätten. Die Summe von 10000 Dollar habe jedoch nur eine Person für sich reklamiert. Schon im August hatte Zuroff demgegenüber darauf hingewiesen, daß ein Este als Gegenreaktion auf die Aktion „last chance“ 20000 Dollar für Hinweise auf bislang unbestrafte jüdische NKVD-Schergen ausgelobt hatte. Sten $A$. Hankewitz, 17 inimest Eestis ja Balti riikides soovib Wiesenthali 10000 dollarit, in: Eesti Päevaleht, 10. September 2002; Efraim Zuroff, Holokaust Eesti meedias, in: Postimees, 6. August 2002.

80 Tarmo Valter, USA võttis kodakondsuse Eestisse kolinud gestaapolaselt, in: Eesti Ekspress, 29. August 2002, A2-A3.

81 Efraim Zuroff, ajalugu ja meie, in: Postimees, 9. August 2002. Zu den zuvor gennanten Aktivitäten vgl. Natsikuritegusid uuriva Simon Wiesenthali keskuse Iisraeli osakonna juht Efraim Zuroff andis täna Tallinnas viibides kaitsepolitseile üle nimekirja seitsmeteistkümnest natsikurjategijast, ETA-Meldung, 10. Juli 2002.

82 Zuroff: "The crimes committed by the Communists in Estonia caused terrible suffering for many Estonians, among them numerous Jews. (Over 440 Jews were deported by the Communists from Estonia in June 1941). These crimes should never be forgotten and it is important to try and bring those guilty of those crimes to justice. But what happened in Estonia was not a Holocaust or even close to one. The suffering of Estonians was appalling, but it does not mean that historically-false symmetries with other far worse suffering should be created. Nor should Estonian suffering at the hands of the Communists be used to excuse or ignore the crimes of those Estonians who collaborated with the Nazis. Those who fought together with the Third Reich have to realize what the implications of a Nazi victory in World War II would have been, even though in many cases they did so more out of hatred for the Soviets, rather than love for Germany." Des weiteren leugnet Zuroff nicht, daß Juden Kommunisten gewesen sein konnten. Sein einseitiges Geschichtsverständnis offenbart sich jedoch in der Bemerkung, dies sei Verrat am jüdischen Volk gewesen: „There were indeed Jews who served Communism and participated in crimes against civilians. They should be accountable for their crimes as should everyone else. But it should be clear that they did so almost inva- 
nicht erwartet werden, daß das sinnlose Gegeneinanderaufrechnen der Greueltaten nationalsozialistischer und sowjetischer Provenienz estnischerseits aufgegeben wird.

Bei diesen verhärteten Fronten ist an eine wissenschaftliche Auseinandersetzung noch nicht zu denken. Typisch bleibt so die (bislang) letzte Episode: In ihrem Forschungsbericht hatte die Historikerkommission unter Jakobsons Leitung festgestellt, daß sich das estnische 36. Polizeibataillon im Sommer 1942 im weißrussischen Novogrudok aufgehalten habe, zu einer Zeit, in der dort über $2000 \mathrm{Ju}$ den erschossen worden sind. Zuroff stützte sich noch in seinem erwähnten onlineInterview auf diesen Bericht und folgerte, daß das Bataillon an den Erschießungen teilgenommen hätte. Auf einer Pressekonferenz mußte nun Jakobson seinerseits demgegenüber klarstellen, daß es „keine Beweise gibt, die eine aktive Beteiligung des Bataillons an dem Mord bestätigen"83. In dieser Form muß sich die Arbeit des Wiesenthal-Zentrums selbst ad absurdum führen - dem Prozeß der Integration des Holocaust in das estnische Geschichtsbewußtsein erweist sie zumindest einen Bärendienst. Kaplinskis Forderung, die noch lebenden Verbrecher vor Gericht zu stellen, sah er selbst in seinem Beitrag vor allem dadurch behindert, daß der durchschnittliche Este es vorziehe, "hinter Barrikaden zu leben“ und es eben nicht als merkwürdig ansehe, wenn „in der Öffentlichkeit diejenigen als Freiheitskämpfer tituliert werden, die unter dem genialen Oberbefehl von Adolf Hitler und Heinrich Himmler an der Ostfront gegen die Rote Armee und im Hinterland gegen rote Partisanen, Juden und Zigeuner"84 gekämpft hätten.

riably not out of any loyalty to the Jewish people, but rather out of loyalty to Communism and a betrayal of the Jewish people. These were individuals who traded in Jerusalem for Moscow, who in most cases turned their backs on their own people and in certain cases actively persecuted Jews. Thus none of these crimes were committed out of Jewish loyalty or on behalf of the Jewish people, which is a very different situation than the cases of the numerous Nazi war criminals from Central and Eastern Europe who thought that they were fulfilling their patriotic duty by collaborating with Nazi Germany and in many instances, mass murdering Jews. " Zuroff selber wäre wohl kaum damit einverstanden, wenn man sich in Estland auf diese Weise von den estnischen Tätern im Zweiten Weltkrieg loszusagen versuchte. Dieses online-Interview vom 8. August 2002, in dem auch einige antisemitsch motivierte Aussagen der anonymen Fragesteller dokumentiert sind, ist nachzulesen in englischer Übersetzung in: > http://www.epl.ee/artikkel.php?ID=210805\&P=1< letzter Zugriff August 2002.

83 Jakobsoni komisjoni ei tea eestlaste rolli massimõrvas, in: Postimees, 24. August 2002.

84 Kaplinski, Mida nad juudid ometi tahavad? 219. Daß im Sommer 2002 in Pärnu ein Ehrenmal für alle im Zweiten Weltkrieg gefallenen estnischen Soldaten - mit einem SS-Soldaten "geschmückt" - für wenige Stunden in Pärnu aufgestellt werden konnte, und sich die Stadtverwaltung nach dem Abbau jeglicher Verantwortung zu entziehen versuchte, zeigt die Virulenz dieser Feststellung. Urmas Seaver, Mirko Ojakivi, Pärnu võttis SS-vormis sōduriga ausamba maha, in: Postimees, 24. Juli 2002; Mirko Ojakivi, SS-ausamba püstitajal olid kooskõlastused, in: Postimees, 1. August 2002. Zu dem Skandal, der sich im Sommer 2004 ereignete, als dieses Denkmal erneut aufgestellt wurde, werde ich mich an anderer Stelle äußern. 


\section{Die ethnische Komponente: Geschichte und Integration}

Ein gutes Jahrzehnt nach der Trennung von der Sowjetunion ist Estland dabei, sich auch historiographisch nach Europa zu orientieren und den engen nationalen Tellerrand zumindest theoretisch in Frage zu stellen. Dies wiederum heißt nicht, $\mathrm{daß}$ die im politischen Sinne ethnisch integrierende Instrumentalisierung von $\mathrm{Ge}$ schichte aus der Zeit der Perestroika überwunden ist. Ohne postmodernen Modellen huldigen $\mathrm{zu}$ wollen, verheißt Jan Ross zufolge das zusammenwachsende Europa für niemanden eine schönere Vergangenheit, „nur mehr, für alle" ${ }^{85}$. Auf dieser Linie liegt auch der in Estland vernehmbare Ruf nach mehr Geschichten. Allerdings muß in diesem Sinne auch die estnische Öffentlichkeit sich mit den weniger heroischen Seiten der eigenen Geschichte auseinandersetzen lernen - ein Prozeß, der auch in den von Estland als Vorbild angesehenen skandinavischen Ländern seine Zeit gebraucht hat (Euthanasie, Kooperation mit dem Dritten Reich).

Nach der durchaus erfolgreichen Rekonstruktion eines ethnisch integrativen Geschichtsbildes ist es in Estland vor allem an der Zeit, der ethnischen Heterogenität des Landes Aufmerksamkeit zu schenken. So sehr in den letzten Jahren die ethnische Komponente von Geschichte in bezug auf die deutsche Vergangenheit in Liv- und Estland thematisiert worden ist, erscheint es demgegenüber für den Integrationsprozeß im Lande selbst aktueller und damit bedeutsamer zu sein, sich mit den stark differierenden Geschichtsbildern von Esten und Russen im Lande auseinanderzusetzen. Nicht die Darstellung estnischer Staatlichkeit oder, um Undusk zu zitieren, die „Geschichte der territorialen Autonomie in Estland“ sollte politische Aufgabe der Historiographie sein $^{86}$, sondern der Einbezug der russischen Minderheit. Unterschiedliche Geschichtsauffassungen stellen die Grundlage der unterschiedlichen Identifikation von Esten und Russen mit der Republik Estland dar. Auch wenn sich manche Parameter verschoben haben dürften, zeigt eine Statistik aus der Mitte der 1990er Jahre, wie stark die Unterschiede in der Einschätzung verschiedener historischer Ereignisse unter Russen und Esten tatsächlich sind ${ }^{87}$ (Tabelle S. 47).

Der neuralgische Punkt des estnischen Selbstverständnisses, die Frage nach der Bewertung des „Anschlusses“ an die Sowjetunion 1940, mag das Problem verdeutlichen: Nach einer neuen Umfrage vertreten $44 \%$ der sogenannten NichtEsten die klassische sowjetische Meinung, daß es sich um einen freiwilligen Beitritt gehandelt habe. Nur 6,5\% benutzen den Begriff „Okkupation“, 26\% den-

85 Jan Ross, Die Vergrößerung der Vergangenheit. Ob es um das Verhältnis zu Israel geht oder um Flucht und Vertreibung nach 1945: Die Geschichtspolitik europäisiert sich, in: Die Zeit Nr. 18, 2002, 52.

86 Undusk bezeichnet eine solche Geschichte des estnischen Staates als "wichtigste Bestellung des heutigen Estland an die Historiker". Undusk, Eesti ajaloo kotkaperspektiivist 110. 87 Michael Geistlinger, Aksel Kirch, Estonia - A new framework for the Estonian majority and the Russian minority, in: Ethnos 45 (1995) 43. 
Bewertungen der bistorisch-nationalen Entwicklung Estlands

\begin{tabular}{llc}
\hline & Esten & Russen \\
\hline Unabhängigkeitszeit 1918-1940 & +78 & +18 \\
Nachbarschaft mit Finnland & +60 & +33 \\
Nachbarschaft mit Schweden & +60 & +24 \\
Nachbarschaft mit Lettland/Litauen & +48 & +16 \\
Einfluß der Exil-Esten & +41 & -2 \\
Einfluß der Deutschen/Baltendeutschen & +24 & -8 \\
Einfluß der Esten in der UdSSR & -13 & +5 \\
Deutsche Okkupation 1941-1944 & -37 & -45 \\
Wachsende Zahl von Nicht-Esten & -45 & -11 \\
Nachbarschaft mit Rußland & -56 & +40 \\
Einfluß der Kommunistischen Partei & -85 & -17 \\
Zugehörigkeit zur UdSSR & -90 & +9 \\
\hline
\end{tabular}

ken, daß es „vielleicht“ eine Okkupation gewesen sei ${ }^{88}$. Um zu verhindern, daß sich unter den Russen wie einst bei den Esten in der Estnischen SSR eine „inoffizielle" alt-neue historische "Wahrheit" herauskristallisiert, sollte aus ersten Überlegungen, wie estnische Geschichte den Russen vermittelt werden könnte ${ }^{89}$, auch ein Umlernprozeß resultieren. Auf das auch manche neueren Schulbücher betreffende Problem, nationale Geschichtsschreibung als politische Waffe gegen eine zahlreiche russische Minderheit im Land zu nutzen, hat auch Jüri Kivimäe kürzlich hingewiesen 90 .

Eine zweisprachige Edition für Lehrer unter dem Titel „Widersprüchliche Geschichte“, wie sie Ieva Gundare in Lettland herausgegeben hat, ist in Estland erst 2004 erschienen. Beispielhaft werden hier „viele Geschichten“ präsentiert, für die Interpretationen z. B. aus nationallettischer, sowjetischer oder exillettischer Perspektive stehen. Paradigmatisch wird zu Beginn des lettischen Bandes festgestellt, daß verschiedene Menschen unterschiedlicher sozialer oder nationaler Herkunft dieselben Ereignisse zwangsläufig anders sehen ${ }^{91}$. Es bleibt zu hoffen, daß ähnliche methodische Ansätze weiterentwickelt werden. In Estland sind Schulbücher, die zum Teil auch in russischer Übersetzung erscheinen, zumeist estozentrisch, d.h. sie blenden die Geschichte der russischen Minderheit aus; sie sind zudem eindeutig faktenorientiert und bieten - abgesehen von bunten Karten und vielen Bil-

88 Angaben von Klara Hallik auf einer Tagung von EUROCLIO und des Estnischen Geschichtslehrerverbands am Narvaer Kolleg der Universität Tartu, 13. September 2002.

89 Eerik-Niiles Kross, Lääne tsivilisatsiooni piiril, in: Eesti Päevaleht, 24. April 2002; Eero Medijainen, Kahestunud ajalooteadvus, in: Eesti Päevaleht, 21. Mai 2002.

90 Kivimäe, Re-writing 207.

91 Protivorečivaja istorija. Posobie dlja učitelja / Pretrunīgā vēsture. Skolotāja rokasgrāmata, hrsg. v. Ieva Gundare (Riga 2000). Vgl. Gundare, Overcoming the Legacy. Die russischsprachige Ausgabe des estnischen Werks: Istorija - èto ne tol'ko prošloe. Prošloe - èto ešče ne istorija. Kniga dlja učitelja istorii (Tallinn 2004). Siehe >www.eas.edu.ee/kasiraamat/rus/ sisu_rus_screen.pdf < letzter Zugriff Juni 2005. 
dern - nur ein äußerst geringes Maß an Didaktik. Aber auch die estnische Historikerzunft ist bislang noch nicht an die Aufgabe herangetreten, eine alle heutigen Bewohner des Landes integrierende Geschichte Estlands zu schreiben. Die Erforschung der Geschichte der russischen Minderheit des Landes bleibt Angelegenheit der russischen Wissenschaftler im Lande, unter denen v.a. der mittlerweile emeritierte Tartuer Professor Sergej G. Isakov zu nennen ist ${ }^{92}$.

Die unterschiedliche Auffassung von Geschichte - die nach Auffassung von Aija Klavina, der Vorsitzenden der lettischen Geschichtslehrervereinigung, fast das ganze 20. Jahrhundert betrifft - trägt stark zu der Verfestigung zweier nebeneinanderher lebender ethnisch bestimmter Gemeinschaften bei. So beschreiben z.B. lettische Russen, die während der Perestroika selbst für Veränderungen eingetreten waren, heute ihre Ambivalenz in bezug auf den lettischen Staat, in dem sie pauschal als „Okkupanten“ klassifiziert werden ${ }^{93}$. Tatsächlich geht es für die ethnisch gespaltenen Gesellschaften in Estland und Lettland weniger um die Frage, ob die deutsche oder die sowjetische Okkupation bösartiger war, sondern vielmehr darum, sich neben der faktischen Aufarbeitung auch um den Einfluß von Mißbrauch und Manipulation von historischen Ereignissen zu kümmern, will man das spaltende Erbe der Geschichte überwinden ${ }^{94}$. Sonst bleibt zum Beispiel der 9. Mai, der Tag des Sieges der Sowjetunion über Hitler, auch in den nächsten Jahren eine ethnisch einseitige russische Veranstaltung, die von den Esten mit Befremden registriert wird, was sich 2005 bestätigt hat.

Gerade die Tatsache, daß die sowjetische Gewohnheit, diesen Tag als Familienfeiertag zu begehen, auch in Estland übernommen wird, so daß - wie auf den hier abgebildeten Fotos vom 9. Mai 2002 am Tallinner Tõnismägi - auch die Enkel und Urenkel der Kriegsteilnehmer feiern, verstört die Esten und verweist auf das traditionsbildende Potential dieser Feierlichkeiten. Eine Tradition, von der sich die Esten ihrerseits wiederum ausschließen.

Obwohl die Debatten, dieses mittlerweile allen im Zweiten Weltkrieg Gefallenen - und damit nicht mehr nur den „sowjetischen Befreiern“ - gewidmete Denkmal abzureißen, offenbar nicht wieder aufkeimen ${ }^{95}$, ist der Abstand zwischen den

$92 \mathrm{Vgl}$. den Band mit Isakovs gesammelten Aufsätzen: Sergej G. Isakov, Russkie v Éstonii 1918-1940. Istoriko-kul'turnye očerki (Tartu 1996), sowie den Sammelband: Russkoe nacional'noe men'šinstvo v Ėstonskoj respublike (1918-1940), hrsg. v. Sergej G. Isakov (Tartu, Sankt-Petersburg 2001).

93 Gundare, Overcoming the Legacy. Vgl. jetzt den Blick der russischsprachigen Minderheit Estlands auf die „singende Revolution“: Iseseisvuse anatoomia, hrsg. v. Rafik Grigorjan, Igor Rosenfeld (Tartu, Sankt-Petersburg 2004).

${ }_{94} \mathrm{Zu}$ diesem Komplex, der hier nur angedeutet werden kann, vgl. Integratsioonimaastik ükskõiksusest koosolemiseni, hrsg. v. Agu Lainus, Iris Pettai, Ivi Proos (Tallinn 2000); Vello Pettai, The Ethnopolitics of Integration in Estonia and Latvia, in >www.ut.ee/ABVKeskus/ balti/ethnopolitics.htm< letzter Zugriff September 2002; Annika Avikson, Estonia on its Way towards a Multicultural Society (B.A. thesis, Universität Tartu 2000), v.a. S. 30-34. Auch in >www.ut.ee/ABVKeskus/eesti/estonia-multicultural_society.doc< letzter Zugriff September 2002.

95 Der vor wenigen Jahren unter Außenminister Ilves begonnene Versuch einer neuen Traditionsbildung kann noch nicht beurteilt werden. Am 9. Mai finden gegenüber dem Außen- 

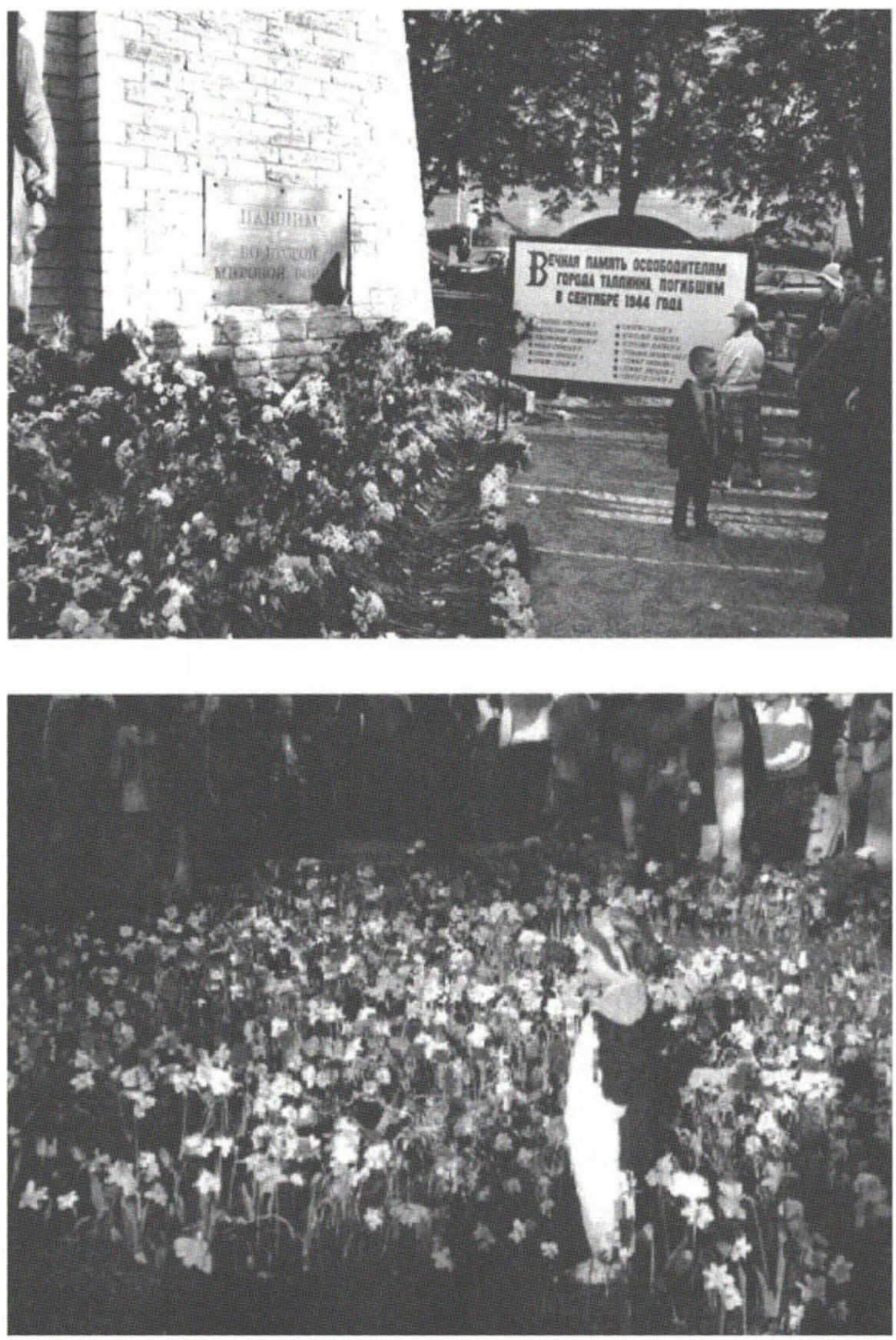

9. Mai 2002, Tallin, Fotos: (C) Karsten Brüggemann. 
Parallelgesellschaften an diesem Tag deutlich zu spüren. Es wird für beide ethnischen Gruppen notwendig sein, die jeweils eigene Geschichte für andere Perspektiven zu öffnen, um zu verhindern, daß sich die Gräben noch weiter vertiefen ${ }^{96}$.

Was bleibt als Fazit? Während die intellektuelle Elite Estlands mit nationalen Symbolen und Traditionen postmodern jongliert, bietet dieser Diskurs der breiten Öffentlichkeit kaum Ansatzpunkte zum Verständnis der Transformationsprozesse. Dies heißt nicht, daß die Veränderungen Gefahr liefen, umkehrbar zu sein. Auch die Wahl des ehemaligen Vorsitzenden des Obersten Sowjets Arnold Rüütel zum Präsidenten, der eher als sein Vorgänger, der polyglotte „Europäer des Jahres“ 1998 Lennart Meri, die Sprache des „einfachen Mannes“ spricht, ist nicht als Ausdruck einer rückwärtsgewandten Nostalgie zu deuten. Seine Wahl im September 2001 diente eher einer neuen Balance innerhalb der Gesellschaft, an deren Spitze sich nun auch die derzeitigen Transformationsverlierer vertreten sehen können. „The national values preserved through the Soviet era lost their validity, while those used to justify reforms were not viewed as the interests of the people, but were perceived as the interests of the government and the élite ${ }^{497}$, schrieben die Medienwissenschaftler Lauristin und Vihalemm zur Erläuterung. Für ihre Historikerkolleginnen und -kollegen bietet die sich entwickelnde offene Gesellschaft viele Freiheiten für inhaltlich spannende und methodisch anregende Forschungen. Eine politische Bedeutung wie in den Wendejahren hat die Geschichte heute jedoch nur noch in Ausnahmefällen und ihre Wirkung auf die Gesellschaft ist stark rückläufig. Aber damit hat Estland wohl auch in dieser Hinsicht „Europa“ bereits erreicht.

ministerium, dort, wo früher das Lenin-Denkmal stand, „Europatage“ mit politischen Reden und Musik für jugendliche Besucher statt.

96 In einer Analyse der russischen Medienlandschaft in Estland kommt Valeria Jakobson zu dem Schluß, daß die russische Presse ihren Lesern nur die Illusion biete, über Estland informiert zu sein. Der Kulturschock beim Eintauchen in die estnische Umgebung werde durch sie nicht gemildert. Valeria Jakobson, The Role of the Russian-Language Media in Estonian Society, in: Baltic Media in Transition, hrsg. v. Peeter Vibalemm (Tartu 2002) 207-221, hier 219.

97 Marju Lauristin, Peeter Vibalemm, The Transformation of Estonian Society and Media: 1987-2001, in: Baltic Media in Transition 17-63, hier 58. 